\title{
BIOLOGICAL EFFECTS OF A LOW-FREQUENCY ELECTROMAGNETIC FIELD ON YEAST CELLS OF THE GENUS SACCHAROMYCES CEREVISIAE
}

\author{
SLADICEKOVA $\mathrm{K}^{1}$, BERETA $\mathrm{M}^{2}$, MISEK $\mathrm{J}^{1}$, PARIZEK $\mathrm{D}^{1}$, JAKUS $\mathrm{J}^{1}$ \\ ${ }^{1}$ Department of Medical Biophysics, Jessenius Faculty of Medicine in Martin, Comenius University \\ in Bratislava, Slovak Republic \\ ${ }^{2}$ Department of Radiological Technology, Faculty of Health, Catholic University in Ruzomberok, \\ Slovak Republic
}

\section{A bs tract}

Background: Although the scientific community is extensively concerned with the effects of the EMF, the unambiguous explanation of its effects on living structures is still lacking.

Goals: The goal of the study was to evaluate the effect of a low-frequency (LF) electromagnetic field (EMF) on the growth and multiplication of the yeast Saccharomyces cerevisiae.

Methods: Yeast cells were exposed to a frequency of $900 \mathrm{~Hz}$ and a magnetic flux density of $2.3 \mathrm{mT}$. The duration of each experiment was 8 hours, in the beginning of the measurement the value of frequency, rms (root mean square) value of electric current (2 A), and magnetic flux density were fixed set on the exposure device. A paired experiment was performed, a sample exposed to EMF, and a sample shielded from the field. Subsequently, samples were taken every two hours, the number of cells was recorded, and then the concentration of the yeast cells was evaluated at time points. The time points reflected the exposure time of the samples exposed to EMF.

Results: The results indicate that LF EMF at given parameters has an inhibitory effect on the growth and multiplication of yeast cells.

Conclusion: Exposure to EMF can cause the differences in growth dynamics between cells exposed to the field and the unexposed ones.

KEYWORDS: non-ionizing radiation, electromagnetic field, low frequencies, biological effects, yeast.

\section{INTRODUCTION}

Non-ionizing radiation has been a topic of interest to the scientific community and the general public for decades. The number of sources of EM radiation has been constantly increasing (e.g. development and use of 5G networks), which raises the need for more extensive research in this area. Non-ionizing radiation does not have the ability to ionize atoms and molecules in the environment, and it is in the frequency range of $0 \mathrm{~Hz}$ to $10^{15} \mathrm{~Hz}$. Artificial sources are all electrical appliances in households, factories, mobile phones, IT equipment, and electrical wiring. Extremely LF electric and magnetic fields are in the range $0-300 \mathrm{~Hz}$ and are emitted from electrical wiring, lamps, and appliances (1).

In addition to thermal effects, non-thermal effects can also occur. Non-thermal effects interfere with the function of the cardiovascular, nervous, and endocrine systems and excretory mechanism. According to some authors, human body can respond with some symptoms of the flu, headaches, fatigue, loss of concentration, behavioral changes, or liver cell degeneration (2-5). The effect of EMF was confirmed in 26 studies (Pall, 2016) that

Corresponding author: Ing. Katarina Sladicekova; e-mail: sladicekova1@uniba.sk

(c) 2021 Sladicekova K. et al.

This work is licensed under the Creative Commons Attribution-NonCommercial-NoDerivs 4.0 License (https://creativecommons.org/licenses/by-nc-nd/4.0/) 
addressed the microwave syndrome which represents the neuropsychiatric effects caused by LF radiation (6). Microwave syndrome, currently known as electromagnetic hypersensitivity (EHS), is a set of multi-organ symptoms that occur upon a single intense or continuous exposure to EMFs. Biological effects have been demonstrated at the molecular level with extremely low intensity of magnetic and radio-frequency (RF) EMFs (7). More than 220 scientists point out that EMFs affect biological structures even at lower intensities than those set out in most international guidelines. The effects include an increased risk of cancer, cellular stress, increased levels of harmful free radicals, genetic damage, structural and functional changes in the reproductive system, learning and memory deficits, neurological disorders, and a negative impact on human well-being (8). The study by Misek et al. (2018) points the need to monitor each new base transceiver station which is a source of low energy but permanent whole-body exposure (9). Blank and Goodman (2009) argue that EMF has the ability to act on human cells and DNA and the cells respond by a stress response (11). Presence of stress proteins is a sign that the cell has encountered something harmful and this situation also occurs when interacting with EMF in the whole EM spectrum. According to Blank and Goodman (2011), DNA seems to operate as a fractal antenna (an antenna that amplifies the frequency range) and, thus, responds to different frequencies. Also, it was found that EMF can disrupt an integrity of DNA, blood cells, nerve cells, or affect arterial blood pressure and pulse rate (10-12). According to Jakusova et al. (2010), the duration of a mobile phone call is related to a burning sensation in the ear area, loss of concentration, and sleepiness (13). The authors also show the particular types of personal protection (14). In another study, EMF with a frequency of $50 \mathrm{~Hz}$ can increase the expression level of yeast genes involved in cell metabolism (15). Novak et al. (2007) also confirmed that the number and growth of yeast of the genus Saccharomyces cerevisiae were reduced upon exposure to LF EMFs (16).

The aim of our study was to determine the effect of extremely low EMF frequencies on growth of yeasts of the genus Saccharomyces cerevisiae. The reason for the research is the desire to understand how it is possible to influence biological structures through an external LF EMF. As there are studies (17) on the presence of endogenous LF EMF around the range $0.4-2 \mathrm{kHz}$ in living organisms, the question of the possible influence of these frequencies on biological processes is relevant.

\section{MATERIAL AND METHODS}

The exposure system consisted of an incubator, an exposure coil, a shielding box, a signal generator, and an input harmonic signal amplifier. The main task of the incubator was to maintain the temperature of the samples, as it was a paired experiment. The incubator made of polystyrene and a polyethylene cover contained two polyethylene cavities inside for sample insertion. In addition to the built-in temperature measurement system, the incubator provided air circulation throughout the system. The exposure coil consisted of a PVC tube on which an enamelled copper conductor was wound in two layers of 100 turns. The geometric dimensions of the coil were: height $150 \mathrm{~mm}$, width $167 \mathrm{~mm}$, and a diameter of the wound conductor $0.9 \mathrm{~mm}$. The yeast was exposed at a rms value of electric current I = 2 A (time course of sine shape) to the magnetic field with magnetic flux density $\mathrm{B}=2.3 \mathrm{mT}$ and frequency $\mathrm{f}=900 \mathrm{~Hz}$, which appeared as an appropriate maximum in the experiments (18). A signal generator (RIGOL DG 4162, Micronix) and a linear amplifier (Hubert A1110-05, Dr. Hubert GmbH) were used to condition the exposure signal. A multimeter was connected for the whole duration of the experiment and we continuously verify the value of the supply current. The control samples were placed in a metal shielding box. The measured magnetic flux density inside the shielding box was six-fold lower comparing to the center of the coil. The aim of shielding was to show in the results the difference between the natural process of multiplication and the growth of yeasts as opposed to the 
effect of EMF. The same conditions (temperature, air supply) were ensured for the control sample as for the exposed one. The temperature inside the incubator was stabilised to $28^{\circ} \mathrm{C}$ during the whole experiment. The temperature was measured in both cavities of the incubator using NTC thermistors. The time of exposure to the EMF was different for individual time points. At 0 hours, paired samples were not exposed. At 2 hours, the exposed (E) sample was exposed for 2 hours and the control (C) sample was shaded for the same exposure time. The samples were then placed back in the incubator and exposed at additional time intervals ( $4 \mathrm{~h}, 6 \mathrm{~h}$, and $8 \mathrm{~h}$ ).

The material used in this study were yeast cells Saccharomyces cerevisiae. They were maintained at a constant temperature of $25^{\circ} \mathrm{C}$ in the laboratory under sterile conditions to achieve the optimal state for propagation and to prevent contamination. The yeast cells were obtained from the Science Park of the University of Zilina under the supervision of the Department of Electrical Engineering and Biomedical Engineering.

In the experiment we used YPD (Yeast Extract-Peptone-D-Glucose) medium which contained distilled water $(95 \%(\mathrm{w} / \mathrm{v})$, peptone $2 \%(\mathrm{w} / \mathrm{v})$, glucose $2 \%(\mathrm{w} / \mathrm{v})$, and yeast extract $1 \%(\mathrm{w} / \mathrm{v})(19)$. The preparation of the medium was followed by a pre-cultivation process lasting 16 hours. We inoculated a small sample containing the yeast (kept refrigerated at $4^{\circ} \mathrm{C}$ ) into a flask with $10 \mathrm{ml}$ of prepared YPD medium. The yeast medium was placed on a shaker. They were cultured for 16 hours at a speed of $180 \mathrm{rpm}$. Pre-cultured yeast solution with a volume of $1 \mathrm{ml}$ was pipetted into two prepared flasks containing $30 \mathrm{ml}$ of medium in each one. A paired experiment was performed with the same initial cell concentration in both samples (time 0 hours). The samples were placed into a dual cavity incubator (Fig. 1). One cavity of the incubator contained a radiation coil and the other cavity a shielding box. The radiation coil is a source of LF magnetic field and achieves approximately 90\% of homogeneity. The flasks were closed with cotton plugs and an air supply was provided.

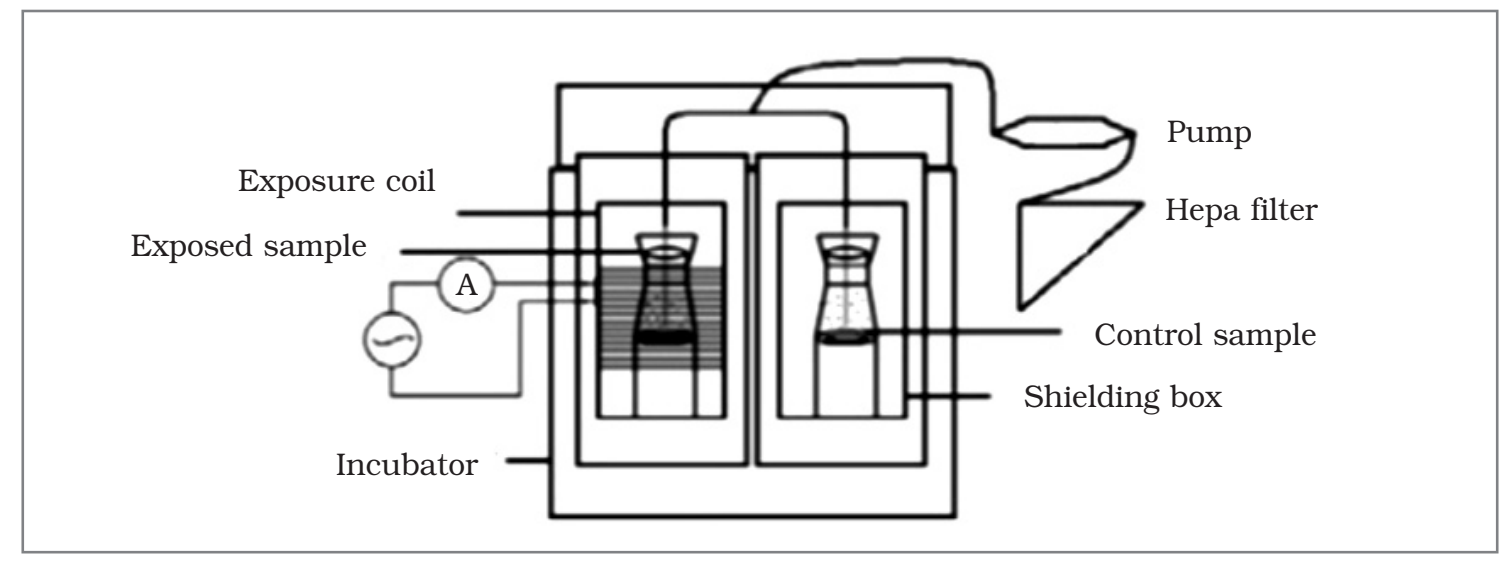

Fig. 1 Schematic representation of the measuring system (20).

The evaluation of growth dynamics was performed by the method of measuring cell concentrations during individual measurements. We observed cell growth (propagation) every two hours after sampling from the $\mathrm{C}$ and $\mathrm{E}$ solutions. Using a microscope (Primovert, Carl Zeiss Microscopy, LLC) we photographed the current number of yeast (Fig. 2). The yeast concentration $c$ was calculated as the ratio of the number of yeast cells $n$ located on one segment (one square in the microscope image) and the volume of the Neubauer chamber segment, the value of which is known as VS $=25 \times 10^{-8} \mathrm{ml}$. In each measurement the number of cells was counted in one square (segment). The arithmetic mean of the number of cells was determined by adding the segments and divided by the number of measurements. 


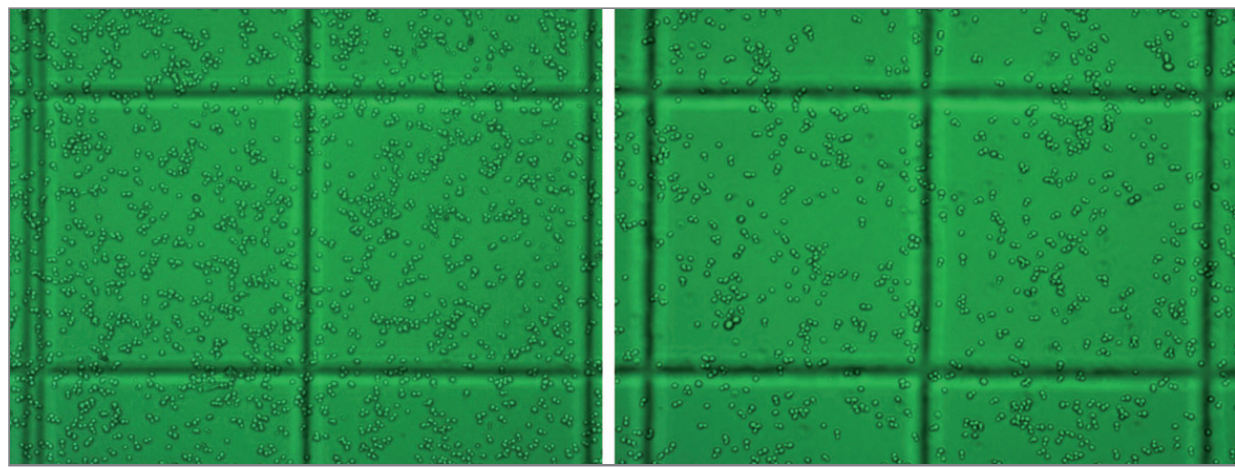

Fig. $2 \mathrm{C}$ and $\mathrm{E}$ samples after 8 hours of EMF exposure at frequency $\mathrm{f}=900 \mathrm{~Hz}$

The values of concentrations passed the test of normality and the Paired test was used. Statistical significance of differences observed among the mean values was determined using Statistical Package for the Social Sciences (SPSS), P $<.05$ was considered significant.

\section{RESULTS}

The data obtained for $\mathrm{C}$ and $\mathrm{E}$ samples for selected time points are summarized in Table 1 and Table 2. According to Table 1 the values point to the fact that at analyzed frequency the $\mathrm{C}$ sample always acquired higher values. This means that the yeast multiplied faster under the maintained conditions in the laboratory (constant temperature, sterile environment) without an exposure to the EMF than in the case of the exposure (the E samples reached a smaller number of yeast cells). The values in Table 1 indicate that in the end

Table 1 Yeast cell concentrations [number of cells $/ \mathrm{ml}]$

\begin{tabular}{|c|c|c|c|c|c|c|c|}
\hline $\mathrm{f}$ & $\begin{array}{l}\text { Measurement } \\
\text { number }\end{array}$ & Sample & $\mathrm{Oh}$ & $2 \mathrm{~h}$ & $4 h$ & $6 h$ & $8 \mathrm{~h}$ \\
\hline \multirow{10}{*}{$900 \mathrm{~Hz}$} & \multirow[t]{2}{*}{1.} & $\mathrm{C}$ & $1.09 \times 10^{8}$ & $2.44 \times 10^{8}$ & $3.04 \times 10^{8}$ & $6.36 \times 10^{8}$ & $9.58 \times 10^{8}$ \\
\hline & & $\mathrm{E}$ & $1.09 \times 10^{8}$ & $2.14 \times 10^{8}$ & $2.09 \times 10^{8}$ & $5.96 \times 10^{8}$ & $8.50 \times 10^{8}$ \\
\hline & \multirow[t]{2}{*}{2.} & $\mathrm{C}$ & $1.24 \times 10^{8}$ & $2.27 \times 10^{8}$ & $3.37 \times 10^{8}$ & $7.23 \times 10^{8}$ & $1.59 \times 10^{9}$ \\
\hline & & $\mathrm{E}$ & $1.24 \times 10^{8}$ & $1.78 \times 10^{8}$ & $2.63 \times 10^{8}$ & $5.54 \times 10^{8}$ & $1.04 \times 10^{9}$ \\
\hline & \multirow[t]{2}{*}{3.} & $\mathrm{C}$ & $1.63 \times 10^{8}$ & $2.44 \times 10^{8}$ & $4.07 \times 10^{8}$ & $5.79 \times 10^{8}$ & $9.69 \times 10^{8}$ \\
\hline & & $\mathrm{E}$ & $1.63 \times 10^{8}$ & $2.12 \times 10^{8}$ & $3.03 \times 10^{8}$ & $4.68 \times 10^{8}$ & $7.42 \times 10^{8}$ \\
\hline & \multirow[t]{2}{*}{4.} & $\mathrm{C}$ & $2.20 \times 10^{8}$ & $2.72 \times 10^{8}$ & $3.97 \times 10^{8}$ & $7.62 \times 10^{8}$ & $1.87 \times 10^{9}$ \\
\hline & & $\mathrm{E}$ & $2.20 \times 10^{8}$ & $2.44 \times 10^{8}$ & $3.67 \times 10^{8}$ & $6.02 \times 10^{8}$ & $1.01 \times 10^{9}$ \\
\hline & \multirow[t]{2}{*}{5.} & $\mathrm{C}$ & $1.62 \times 10^{8}$ & $2.26 \times 10^{8}$ & $3.30 \times 10^{8}$ & $4.29 \times 10^{8}$ & $7.82 \times 10^{8}$ \\
\hline & & $\mathrm{E}$ & $1.62 \times 10^{8}$ & $1.82 \times 10^{8}$ & $2.72 \times 10^{8}$ & $3.20 \times 10^{8}$ & $5.74 \times 10^{8}$ \\
\hline
\end{tabular}

Abbreviations: E exposed sample, $\mathrm{C}$ control sample, $\mathrm{f}$ frequency. 
of the measurement the concentration of cells in the $\mathrm{C}$ sample increases significantly compared to the $\mathrm{E}$ one. A slight inhibition persisted between 2 and 6 hours but the difference is especially notable between 6 and 8 hours (Figure 3).

In each of the measurements it was confirmed that the cell concentration in the E sample was always lower than in the C due to the LF EMF (Fig. 4). The mean C and E values, as well as concentration ratios of the samples at the selected time point from all performed measurements, are in Table 2. The arithmetic mean of the ratios of the concentrations of $\mathrm{E}$ and $\mathrm{C}$ cells in the end of the experiments for $\mathrm{f}=900 \mathrm{~Hz}$ is $0.716 \pm 0.13(\mathrm{p} \leq 0.0482)$.

Table 2 The mean values of cell concentration and concentration ratios from all measurements for selected time points. Paired test

\begin{tabular}{|c|c|c|c|c|c|}
\hline Exposure & $\begin{array}{c}\text { Exposure } \\
\text { time }\end{array}$ & $\begin{array}{c}\text { Control sample } \\
\text { (Mean } \pm \text { SD) }\end{array}$ & $\begin{array}{c}\text { Exposed sample } \\
\text { (Mean } \pm \text { SD) }\end{array}$ & $P$ Value & $\begin{array}{c}\text { E/C concentrationratios } \\
\text { (Mean } \pm \text { SD) }\end{array}$ \\
\hline \multirow{3}{*}{$900 \mathrm{~Hz}$} & 0 hours & $1.56 \times 10^{8} \pm 0.43$ & $1.56 \times 10^{8} \pm 0.43$ & N/A & $1 \pm 0.00$ \\
\cline { 2 - 6 } & 2 hours & $2.43 \times 10^{8} \pm 0.19$ & $2.06 \times 10^{8} \pm 0.27$ & $0.0009^{*}$ & $0.85 \pm 0.05$ \\
\cline { 2 - 6 } & 4 hours & $3.55 \times 10^{8} \pm 0.45$ & $2.83 \times 10^{8} \pm 0.58$ & $0.0055^{*}$ & $0.79 \pm 0.09$ \\
\cline { 2 - 6 } & 6 hours & $6.26 \times 10^{8} \pm 1.31$ & $5.08 \times 10^{8} \pm 1.18$ & $0.0069^{*}$ & $0.81 \pm 0.08$ \\
\cline { 2 - 6 } & 8 hours & $12.34 \times 10^{8} \pm 4.70$ & $8.43 \times 10^{8} \pm 1.93$ & $0.0480^{*}$ & $0.72 \pm 0.13$ \\
\hline
\end{tabular}

Abbreviations: *Statistically significant difference.

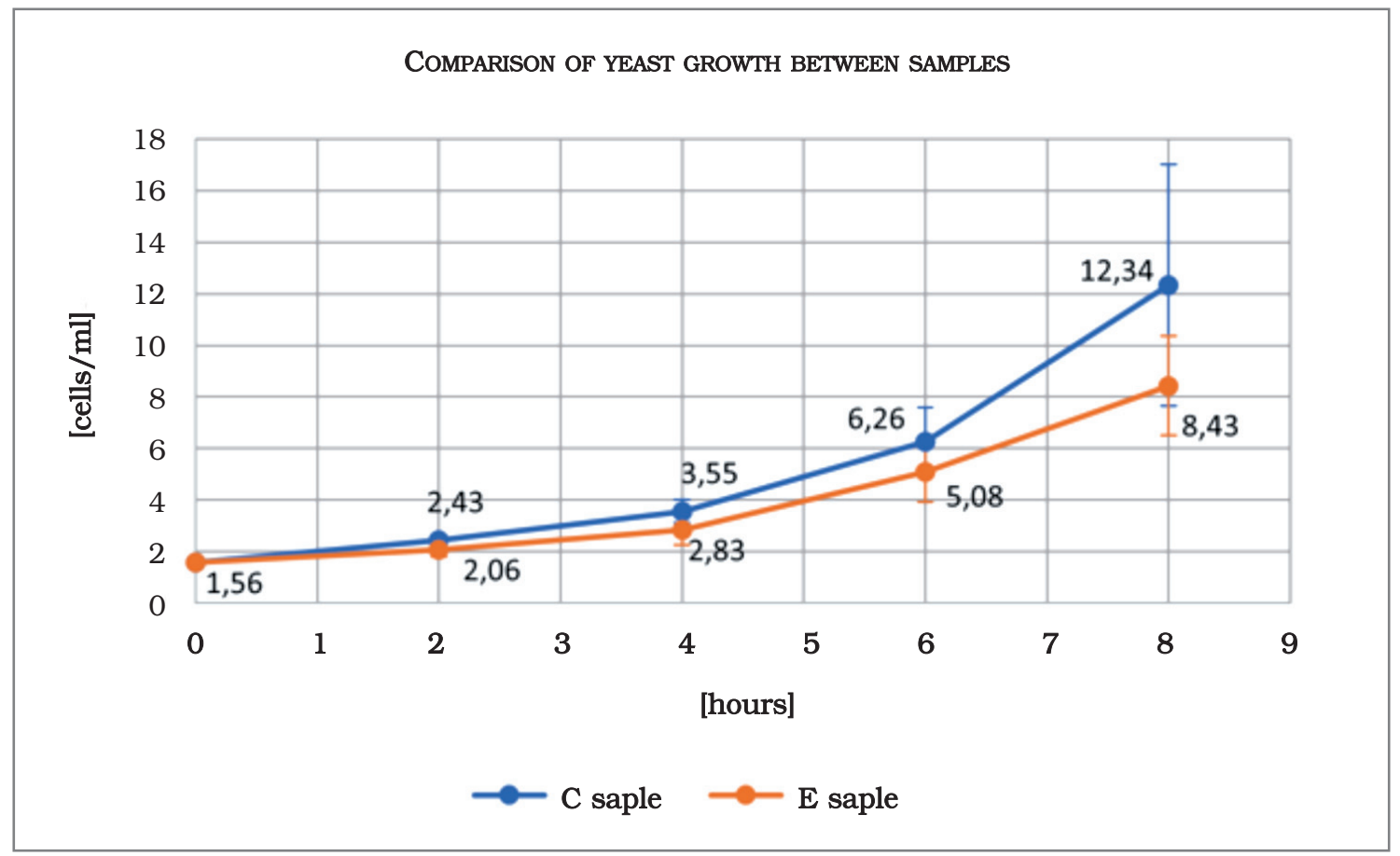

Fig. 3 Comparison of yeast growth at a frequency of $900 \mathrm{~Hz}$ 


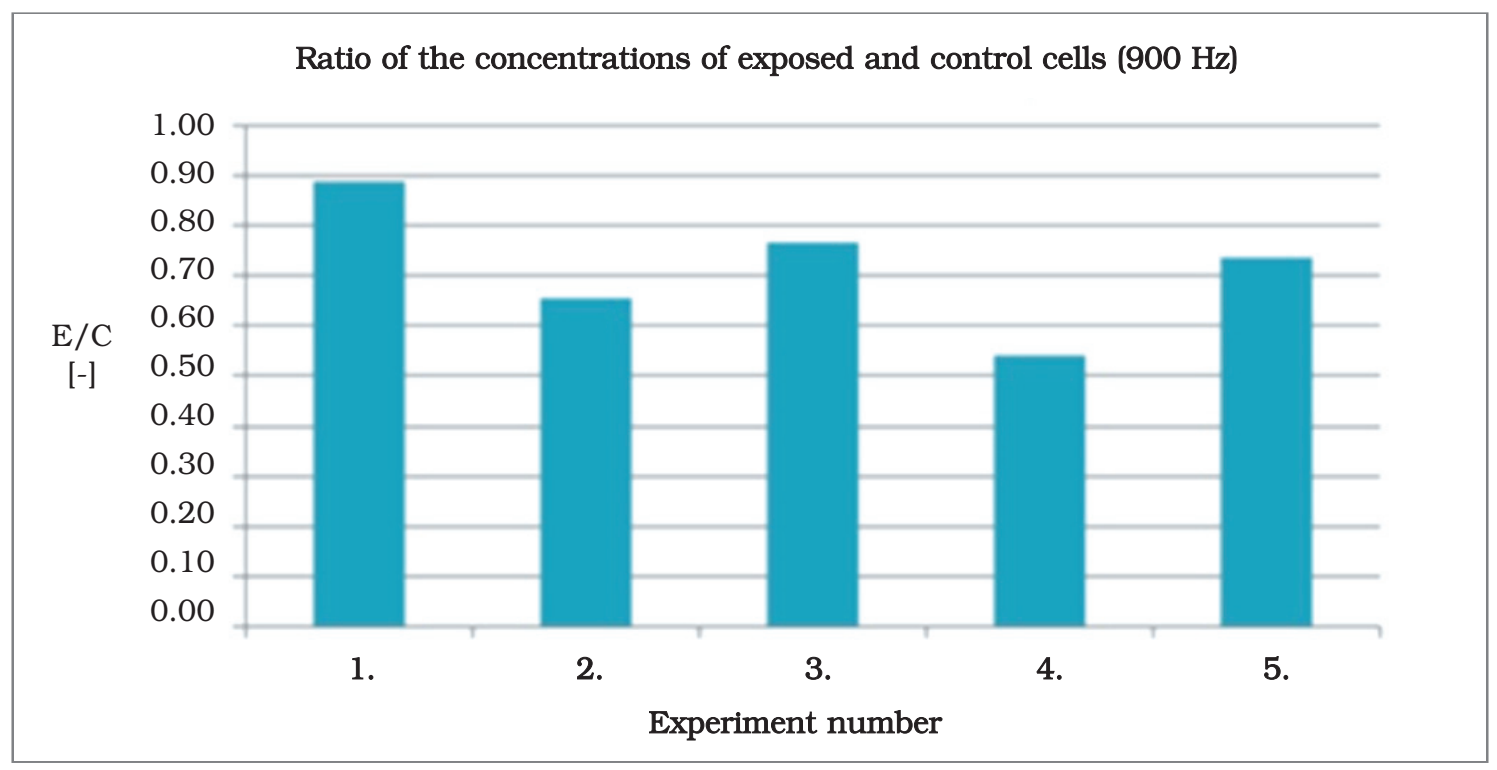

Fig. 4 The ratio of the concentrations of $\mathrm{E}$ and $\mathrm{C}$ samples after 8 hours

\section{DISCUSSION}

The results of this study suggest that the LF EMF at the given parameters of the experiment has an inhibitory effect on the growth of yeast cells. With increasing exposure time and parallel control culture an increase in the variance of cell numbers can be observed, which is characterized by a standard deviation. E/C concentration ratios reach a value lower than 1.0, which also confirms the previous assumption of the inhibitory effect. The highest decrease in yeast cell growth in the $\mathrm{E}$ sample compared to the $\mathrm{C}$ sample was found at a frequency of $900 \mathrm{~Hz}$ between 6 and 8 hours (31.69\%). This was followed by a decrease of $20.28 \%$ between 2 and 4 hours, a decrease of $18.85 \%$ between 4 and 6 hours, and the smallest difference between the samples was $0-2$ hours (15.23\%). An interesting fact is that the SD increased significantly over time, which is actually seen in the decreasing $\mathrm{P}$ value. Several other studies have shown a frequency- dependent response of yeast. The effect of EMF on Saccharomyces cerevisiae was studied by Barabas et al. (2015), where an inhibitory effect of EMF on yeast cell growth was also observed at similar exposure parameters employing another method for evaluation of growth dynamics (18). Also, based on the study of Bereta et al. (20), which used the same evaluation method - Neubauer counting chamber, but was targeted to a different EMF frequency $(1600 \mathrm{~Hz})$, slower growth of yeast was confirmed. Our study combined the findings of both researches and confirmed the hypothesis that LF EMF has the ability to affect biological structures in the process of growth and reproduction. The results of the study were obtained at a frequency of $900 \mathrm{~Hz}$, this allows further discussion of the possible action in the LF bands of EMF and their subsequent comparison or evaluation of which frequency achieves the highest inhibition, which may be the aim of another study. Also, further experiments could be aimed to observe biological effects at other parameters of magnetic flux density.

Although the effects of LF EMF on the growth of yeast is not a purely medical topic, the impact of this field has significantly affected human health in recent years. The human body is constantly exposed to subthreshold values of non-ionizing RF radiation. With the development of 5G networks comes the installation of antenna systems that will contain thousands of mini- antennas multiplying radiation. The EHS disease gives an area 
of deeper investigation into the negative effects of EM radiation on some individuals. A study by Míšek et al. (2018) showed e.g. that students exposed to a short-term exposure of the head to RF EMF had significantly increased parasympathetic nerve activity compared to the control group when passing the ortho-clinostatic test affected by ANS in the lying position (21). Recent findings in the field of microbiology point to the fact that bacterial strains also respond differently to EMFs (modified bacterial growth or antibiotic resistance). Taheri et al. (2017) claim that an exposure of bacteria to a Wi-Fi router and RF simulator can cause the resistance of microorganisms to antibiotics. There has also been an inhibitory effect on the growth of $L$. monocytogenes and $E$. coli, which may have a significant effect on the management of infectious diseases (22). A different response to the action of EMF on microorganisms was also noted by Movahedi et al. (2019), where a mobile simulator emitted waves of $900 \mathrm{MHz}$ frequency and indicated an increase in bacterial resistance in S. aureus and $P$. aeruginosa (23). The study by Crabtree et al. (2017) discusses the hypothesis that RF EMF from mobile phone can disrupt the microbiota of human skin (24). In summary, the action of EM radiation interferes with the biological processes of the microbiota and may result in pathological changes of the human body. Technological progress is unstoppable, however and only intensive research in this field may protect human health.

\section{CONCLUSIONS}

In our study, yeast cells of the genus Saccharomyces cerevisiae were exposed to LF EMF with a frequency of $900 \mathrm{~Hz}$. A significant inhibitory effect of EMF (magnetic flux density $2.3 \mathrm{mT}$, rms value of electric current $2 \mathrm{~A}$, frequency $900 \mathrm{~Hz}$, EMF exposure time $0 \mathrm{~h}, 2 \mathrm{~h}$, $4 \mathrm{~h}, 6 \mathrm{~h}$, and $8 \mathrm{~h}$ ) on the reproduction and growth of unicellular organisms was observed by using a comparative method. The results indicated that at given values the LF EMF has inhibitory effects on the life cycle of the yeast cell. Thus, it is appropriate to extend the study to include additional exposure tests with other frequencies.

\section{REFERENCES}

1. Jakusova V. Ultraviolet radiation and mobile communication: physical characteristics, biological effects and health protection: scientific monograph (in Slovak). 1 ${ }^{\text {st }}$ ed. Bratislava: Samosato; 2009. 97 p. ISBN 978-80-89464.

2. Novak I. Effects of electromagnetic field on the human body. Elektroinstalatér. [online]. 2015; 21 (5): [cit. 2021-05-15]. Available from: http://elektro.tzb-info.cz/13319-ucinky-elektromagnetickeho-pole-na-lidsky-organismus

3. Bobko M. Problems of electromagnetic field in the working environment. [online]. ŠZÚ Košice. [cit. 2021-05-15]. Available from: http://www.ruvzbj.sk/oddelenia.files/ppl_a_toxikologia.files/pplzdrav-vych.mat/emg_pole.html

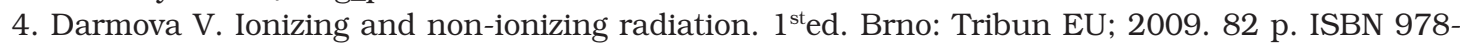
80-7399-814-1.

5. Belyaev I, Dean A, Eger H, et al. EUROPAEM EMF Guideline 2016 for the prevention, diagnosis and treatment of EMF-related health problems and illness. Rev Environ Health 2016; 31(3): 363-97.

6. Pall ML. Microwave frequency electromagnetic fields (EMFs) produce widespread neuropsychiatric effects including depression. J Chem Neuroanat 2016; 75(Pt B): 43- 51.

7. Stein Y, Udasin I.G. Electromagnetic hypersensitivity (EHS, microwave syndrome) - Review of mechanisms. Environmental Research 2020; 186: 109445.

8. Rojkova V. I. I've been looking for a cursor for a minute ... and a path my whole life. Bratislava: Izkona; 2020. 159-203 p. ISBN 9788097323844.

9. Misek J, Laukova T, Kohan M, Veternik M, Jakusova V, Jakus J. Measurement of low-level radiofrequency electromagnetic fields in the human environment. Acta Medica Martiniana 2018; 18(2): 27-33. 
10. Blank M. Protein and DNA reactions stimulated by electromagnetic fields. Electromagn Biol Med 2008; 27(1): 3-23.

11. Blank M, Goodman R. Electromagnetic fields stress living cells. Pathophysiology. Electromagn Biol Med 2009; 16(2-3): 71-8.

12. Blank M, Goodman R. DNA is a fractal antenna in electromagnetic fields. Int J Radiat Biol 2011; 87(4): 409-15.

13. Jakusova V, Poliacek I, Osina O, Valach M, Jakus J. Mobile communication - possible risks and health protection of university students. Acta Medica Martiniana 2010; 7(2): 3-10.

14. Jakusova V, Murajda L, Poliacek I, Jakus J. Risk of ultraviolet radiation - health protection of university students. Acta Medica Martiniana 2010; 10(1): 26-30.

15. Lin KW, Yang ChJ, Lian HY. Exposure of ELF-EMF and RF-EMF Increase the Rate of Glucose Transport and TCA Cycle in Budding Yeast. Front Microbiol 2016; 7: 1378.

16. Novak J, Strasak L, Fojt L, Slaninova I, Vetterl V. Effects of low-frequency magnetic fields on the viability of yeast Saccharomyces cerevisiae. Bioelectrochemistry 2007; 70(1): 115- 21.

17. Bukhari M. Intrinsic electromagnetic noise in living cells in vitro and its spectroscopy. Journal of Basic and Applied Sciences 2009; 5(2): 65-71.

18. Barabas J, Radil R, Malikova I. Modification of S. cerevisiae growth dynamics using low frequency electromagnetic fields in the $1-2 \mathrm{kHz}$ range. BioMed Research International 2015; 2015 : 694713.

19. Sherman F. Getting started with yeast. Methods in Enzymology 2002; 350: 3-41.

20. Bereta M, Balcova E, Janousek L. Barabas J. Low frequency electromagnetic field effects on growth dynamics of yeast cells. Acta Technica Corviniensis 2017; 2067: 3809.

21. Misek J, Belyaev I, Jakusova V, Tonhajzerova I, Barabas J, Jakus J. Heart rate variability affected by radiofrequency electromagnetic field in adolescent students. Bioelectromagnetics 2018; 39:4: 277-288.

22. Taheri M, Mortazavi SMJ, Moradi M, Mansouri S, Hatam GR, Nouri F. Evaluation of the Effect of Radiofrequency Radiation Emitted From Wi-Fi Router and Mobile Phone Simulator on the Antibacterial Susceptibility of Pathogenic Bacteria Listeria monocytogenes and Escherichia coli. Dose Response 2017; 15(1): 1559325816688527.

23. Movahedi MM, Nouri F, Golpaygani AT, Ataee L, Amani S, Taheri M. Antibacterial Susceptibility Pattern of the Pseudomonas aeruginosa and Staphylococcus aureus after Exposure to Electromagnetic Waves Emitted from Mobile Phone Simulator. J Biomed Phys Eng 2019; 9(6): 637-646.

24. Crabtree DPE, Herrera BJ, Kang S. The response of human bacteria to static magnetic field and radiofrequency electromagnetic field. Journal of Microbiology 2017; 55: 809-815.

\section{Acknowledgment}

This work was supported by project: ITMS: 26210120021 , co-funded from EU sources and European Regional Development Fund. This study was also supported by Slovak Research and Development Agency under the contract no. APVV-19-0214 and project VEGA 1/0173/20 and Comenius University grant no. UK/128/2021.

Received: June, 15, 2021

Accepted: July, 25, 2021 